\title{
OPTIMIZATION PLAN FOR EXCESS WAREHOUSE STORAGE IN E-COMMERCE-BASED PLANT SHOPS: A CASE STUDY FOR CHINESE PLANT INDUSTRIAL
}

\author{
Hung-Lung LIN ${ }^{(1)}{ }^{1}$, Cheng-Chung $\mathrm{CHO}^{(D)} 3^{*}$, Yu-Yu MA (D) \\ Ying-Qing HU(D) ${ }^{5}$, Ze-Hui YANG (D) 1 \\ ${ }^{1}$ College of Management and Engineering, Huaiyin Institute of Technology, No. 1, \\ Meicheng Rd. Huaian 223003, Jiangsu, P. R. China \\ ${ }^{2}$ Jiangsu Smart Factory Engineering Research Center, Huaiyin Institute of Technology, \\ No. 1, Meicheng Rd. Huaian 223003, Jiangsu, P. R. China \\ ${ }^{3}$ Department of Ocean and Border Governance, National Quemoy University, \\ No. 1, University Rd., Jinning Township, Kinmen County 892, Taiwan \\ ${ }^{4}$ College of Foreign Languages, Huaiyin Institute of Technology, \\ No.1, Meicheng Rd. Huaian 223003, Jiangsu, P. R. China \\ ${ }^{5}$ College of Applied Technology, Huaiyin Institute of Technology, \\ No.1, Meicheng Rd. Huaian 223003, Jiangsu, P. R. China
}

Received 8 September 2018; accepted 18 April 2019

\begin{abstract}
The rapid development of e-commerce in China has played a critical role in the development of the national economy and ongoing modernization. The plant industry is unique among industries that employ e-commerce sales models because its products exhibit special characteristics such as high death and damage rates. Therefore, its e-commerce and logistical requirements are stricter than in other industries and, as a result, excess warehouse storage can be extremely difficult for e-commerce-based plant shops to manage. Numerous studies have indicated the need to identify a product's most up-to-date market conditions, as well as the type, function, and size of warehouses. Therefore, based on a case study, this study proposes an optimization plan for solving excess warehouse storage in e-commerce-based plant shops. First, sales volume data of the case company, Enterprise A, were analyzed to predict future sales. Then, entropy and the technique for order preference by similarity to an ideal solution were used to construct the decision-making model. Finally, a cloud warehouse-based optimization plan was proposed to solve excess warehouse storage in e-commerce-based plant shops. This plan can serve as a reference for decision-makers or executives in e-commerce-based plant shops when handling excess warehouse storage.
\end{abstract}

Keywords: plant industry, excess warehouse storage, cloud warehouse, exponential smoothing, multiple criteria decision making (MCDM).

JEL Classification: L81, M10, C22, C44, C53, D7.

\footnotetext{
*Corresponding author. E-mail: hsa8936@msn.com
} 


\section{Introduction}

E-commerce in China has played a critical role in the development of the national economy and ongoing modernization. The plant industry is unique among industries that employ e-commerce sales models because its products exhibit special characteristics such as high death and damage rates. Therefore, its e-commerce and logistical requirements are stricter than in other industries and, as a result, excess warehouse storage can be extremely difficult for e-commerce-based plant shops to manage. Numerous studies have indicated the need to identify a product's most up-to-date market conditions, as well as the type, function, and size of warehouses.

Excess warehouse storage mainly stems from the failure of grasping and sharing market demand and dynamics in the entire supply chain; in consequence, affecting all the logistics operating process. In this study, an optimization model framework is offered to solve excess warehouse storage in e-commerce. A detailed computation examinations of the proposed framework is provided, and real cases were used for analysis. To verify the applicability of the proposed model, analysis was made to clarify whether the concept of "cloud warehouse" is able to help tackle the barrier. These results will be describe on case implementation and benefit and to verify academic theory is can be real apply to solve problem on commence practice. In the study, first a case study was examined and its results analyzed using a prediction model, the accuracy of which was subsequently verified. After that, the results of the prediction models are made to determine the capacity of the proposed storage facility. Finally, according to the needs of the case, we used decision-making models to evaluate among three different warehouse construction proposals are made for bringing forward the solutions of excess warehouse storage and logistics warehouse construction so as to serve as a reference standard for Enterprise A. Crucially, the proposed model provides decision-makers or administrators in the plant industry with valuable references related to e-commerce sales and excess warehouse storage strategies, rendering it highly applicable for academic and management purposes.

To sum up, the introduction of this study clearly introduces the research purposes and motivation, and the main research structure and core will be specifically described in the following five parts: Section 1 -background and literature, Section 2 - optimization models for resolving excess warehouse storage, Section 3 - case implementation and analysis, Section 4 - results and suggestions and Section 5 - discussion. Finally, the conclusion part will clearly summarize the main aspects, then put forward limitations and suggestions for future researches.

\section{Background and literature}

With economic development and increasing incomes, people are becoming increasingly aware of the importance of enhancing quality of life. Many people have begun using plants to decorate their homes or offices to enhance physical and psychological health. According to the China's e-Commerce Research Center (2018), the annual trading volume in plants increased from RMB $\$ 26$ billion in 2014 to RMB $\$ 139.13$ billion in 2017. Moreover, the market 
grew at a rate of $75.1 \%$ annually, indicating that the plant market has an infinite potential for development. Given this trend and the change in consumption habits due to advances in Internet technology, the market demand for plants has increased and electronic commerce (e-commerce) has prospered. Numerous plant industries have transformed to a sales model integrating brick-and-mortar shops with third-partner e-commerce sales platform to expand sales channels, respond to changes, and increase revenues. Plant enterprises are actively adapting to market changes. By continually upgrading their sales model and developing e-commerce service platforms, they can adapt to rapid market changes and survive in a highly competitive environment. Compared with conventional brick-and-mortar plant shops, those integrated with e-commerce (e-commerce-based plant shops) require fewer operating costs, which is why an increasing number of shops are becoming engaged in e-commerce.

The rapid development of e-commerce in China has played a critical role in development of the national economy and ongoing modernization. Electronic online trading has replaced the traditional physical market as an operating model, enhancing both sales volume and convenience. However, this model also causes problems regarding logistics operations. Studies have indicated that the major problems of e-commerce sales models include stagnation in logistics activities caused by excess warehouse storage. J. Liu, C. Liu, Zhang, and $\mathrm{Xu}$ (2019) indicated these include slow delivery, an excess number of express cases, late sorting, and jamming of goods waiting to be shipped out. In extreme cases, these problems can bring about the entire logistics system to crash, thereby damage an enterprise's profits and reputation (Ramanathan, 2010). Many studies have proposed some concepts, methods or models to solve the problem of excess warehouse storage. For example, Wakabayashi, Suzuki, Watanabe, and Karasawa (2014) analyzed and suggested an e-commerce logistics solution and proposed cloud computing based warehouse management system by using warehouse management system (WMS) in Japan. Yang, Lan, and Huang (2019) proposed a new paradigm in which a third party-warehousing equipment supplier is introduced with their advanced facility and technical capability by using WMS. Bao, Huang, Ma, Zhang, and Lv (2012) proposed a concept on the supply chain management supported by e-commerce service platform for agreement based circulation of fruits and vegetables. $\mathrm{Hu}$ (2018) proposed a theoretical framework for e-commerce big data computing platform system based on distributed computing logistics information. Hu and Chang (2010) designed an innovative automatic storage and retrieval system for B2C e-commerce logistics. Koster, Johnson, and Roy (2017) presented a method for warehouse design and management. Zhang, Huang, Xu, and Zhao (2016) proposed an optimization model based on transportation service trading in B2B e-commerce logistics. Jiao (2016) pointed that to solve the phenomenon of excess warehouse storage, enterprises must quicken their response in peak season by improving the last-mile delivery service, reduce the distribution pressure of packages in warehouses at all levels, and enhance the flexibility of their logistics service. Liu (2018) proposed the cloud model theory for evaluation of e-shop transshipment selection in the same network shopping mall to solve the problem of excess warehouse storage. Dianawati, Surjandari, and Nafitri (2012) proposed the forecasting model to solve excess warehouse storage based on the characteristics of historical data in seasonal demand patterns. In view of this phenomenon, to solve the problem of excess storage in logistics systems, communication of information 
between enterprises using e-commerce and logistics enterprises must be improved. Liu et al. (2019) proposed enterprises using e-commerce should adopt scientific methods, such as data collection and statistics simulation, to estimate sales volume during special periods and share these estimates with logistics enterprises so that they are able to prepare in advance to cope with peak-time express volumes. Therefore, demand prediction analysis is commonly performed in the e-commerce industry. A key factor in grasping market changes is timely information sharing, which depends on construction of a sound logistics information platform. However, the plant industry represents a special case in e-commerce in terms of its sales model. Because of the nature of the goods (which can easily die or be damaged), the parties involved must obtain timely updates of the product market and consider the types, functions, and size of warehouses to solve the problem of excess warehouse storage.

In the past, many studies have proposed a lot of concepts, methods and models relating to excess warehouse storage. The advantage is that the past research provided valuable reference for the follow-up academic theoretical research and practical application. However, the disadvantage is that the past researches were mostly limited to the academic concepts, methods and models, and were rarely put into practice, for example, how to help an enterprise overcome an ongoing problem of excess warehouse storage. In particular, there is no research on the problem and solution of excess warehouse storage stems from the e-commerce sales model in plant industry. Furthermore, for the products' particularity, such as easy to withered or easy to be damaged, as a unique e-commerce sales model, plant industry needs not only to consider the solutions proposed in the past, but also to put the type, function and size of the warehouse into consideration. Therefore, based on the theoretical concepts, methods and models put forward in the past studies, this study will solve the problem of excess warehouse storage faced by Enterprise A through a practical case.

\section{Optimization models for resolving excess warehouse storage}

This study focused on Enterprise A, registered in Shuyang County, Jiangsu Province, China. Shuyang County has long been renowned for plant-growing in China. This enterprise has played a critical role among Shuyang businesses that adopting e-commerce as their primary model of operations. On the basis of the research results, this study aimed to provide optimization plans for resolving excess warehouse storage in e-commerce-based plant shops. The forecast model and decision-making model are proposed to solve the problem of excess warehouse storage in enterprise A, and the proposed framework is shown in Figure 1. First, Enterprise A's 2016-2017 sales volume was analyzed to predict future sales. The predicted sales volume was then used to estimate the area and capacity of the warehouses required to solve future excess warehouse storage problems. Subsequently, entropy and the technique for order preference by similarity to an ideal solution (TOPSIS) were used to construct a decision-making model, and practical plans for solving excess warehouse storage were evaluated. Finally, concrete optimization plans and strategies for solving the problem were proposed. Analysis of these plans and strategies are elaborated in the case implementation and analysis section. The following section describes the models adopted in this study. 
Research approach

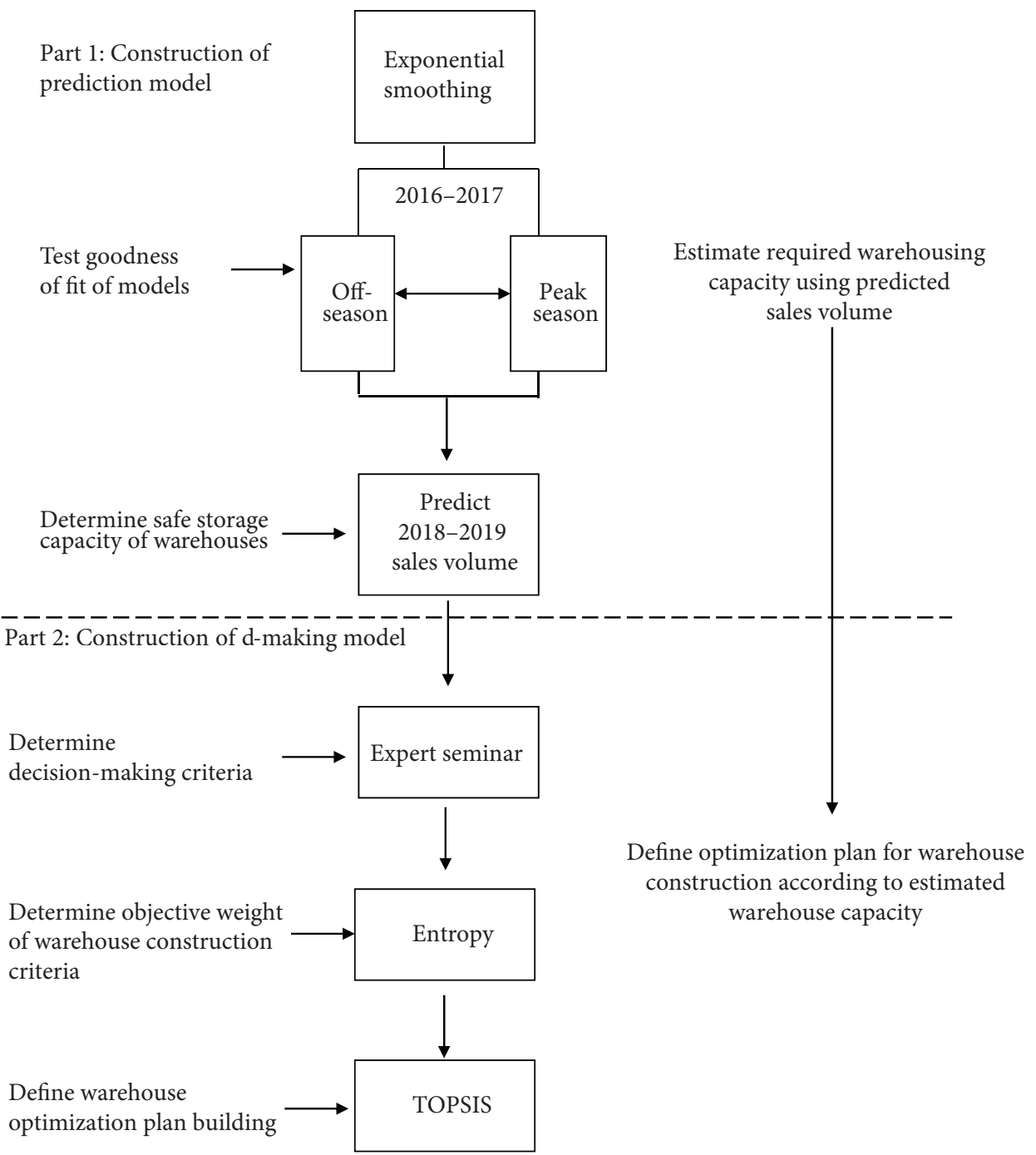

Figure 1. The proposal framework for optimization models to resolve excess warehouse storage based on the e-commence 


\subsection{Constructing the prediction model}

Time-series models are often used in prediction in different fields. For example, Liu et al. (2019) proposed to use the time-series model to predict the sales situation of e-commerce enterprises, and the predicted results can be used for the warehouse plan in advance. The commonly used time-series model is exponential smoothing model. An exponential smoothing model is also referred to as an exponentially weighted moving average. Therefore, a pattern of time-series data exhibits stability and regularity, time-series data can be inferred on a reasonable basis (Hyndman, Akram, \& Archibald, 2008; Vercher, Corberan-Vallet, Segura, \& Bermudez, 2012). Specifically, the latest trend in the data can be extended to the near future to some degree and therefore be designated with relatively large weights (Hyndman et al., 2008; Vercher et al., 2012).

The rationale for exponential smoothing model is as follows. The exponential smoothing value for any period can be expressed as the weighted average of the difference between the exponential smoothing value of the previous period and the actual estimate of the current period. Through layer-by-layer smoothing calculation of historical data series for the prediction target, influences of random factors can be eliminated and the basic change trends of the prediction target identified and used for future predictions. Generally, the prediction model for single exponential smoothing is constructed first, with a double exponential smoothing prediction model subsequently constructed on the basis of the single exponential smoothing results. The equation for a single exponential smoothing prediction model is as follows (Hyndman et al., 2008; Vercher et al., 2012):

$$
\hat{y}_{t+1}=\alpha y_{(t)}+(1-\alpha) \hat{y}_{t},
$$

where $y_{t}$ is the actual value of period $t, \hat{y}_{t}$ the predicted value of period $t, \hat{y}_{t+1}$ the predicted value of period $t+1$, and $\alpha$ the smoothing coefficient representing the weighted index, whose value range is $[0,1]$. The greater $\alpha$ is, the greater becomes the weight of the current-period sales volume, and the more the next-period predicted value is susceptible to the influence of the next-period predicted value, rather than the current-period predicted value.

Because exponential smoothing is a time-series prediction method, for time-series data with obvious linear trends simply using single exponential smoothing is insufficient. To reduce error and approximate the predicted value more to the actual value, the double exponential smoothing prediction model expressed in the following equation can be adopted:

$$
\hat{y}_{t+T}=a_{t}+b_{t} T, T=1,2, \ldots, n,
$$

where

$$
\begin{gathered}
a_{t}=2 S_{t}^{(1)}-S_{t}^{(2)} ; \quad b_{t}=\frac{\alpha}{1-\alpha}\left(S_{t}^{(1)}-S_{t}^{(2)}\right) ; \\
S_{t}^{(1)}=\alpha y_{t}+(1-\alpha) S_{t-1}^{(1)} ; \quad S_{t}^{(2)}=\alpha S_{t}^{(1)}+(1-\alpha) S_{t-1}^{(2)} .
\end{gathered}
$$

In these equations, $S_{t}^{(1)}$ is the single exponential smoothing value of period $t, S_{t}^{(2)}$ is the double exponential smoothing value of period $t$, and $a_{t}, b_{t}$ are the smoothing coefficients of the double exponential smoothing model. 
In actual application of an exponential smoothing model, the most critical step is selecting the value of the weight $\alpha$. Generally, the greater the changes in the smoothing level are, the greater $\alpha$ becomes, thereby enabling exponential smoothing prediction to perform quick adjustments. Conversely, the greater the data randomness is, the smaller the selected value of $\alpha$ should be, to enable more noise removal and trend smoothing. The value of $\alpha$ is selected according to the characteristic changes in the time series. If the time-series fluctuation is relatively mild and steady, then a relatively small $\alpha$ range should be selected, such as $[0.1,0.3]$. However, if the time series exhibits a trend of rapid and distinct changes, then a relatively large $\alpha$ range should be selected, such as $[0.5,0.9]$.

Actual application of the exponential smoothing model in this study showed that data fluctuations in the research subject were relatively obvious; therefore, an $\alpha$ range of $[0.5,0.9]$ was selected for prediction testing.

\subsection{Constructing the decision-making model}

Multiple criteria decision making (MCDM) is a methodology used to solve complex problems (Hoseinpour, Sadrnia, Ghobadian, \& Tabasizadeh, 2019). Entropy and TOPSIS in MCDM have been widely applied to solve complex project selection and evaluation. Examples are as follows, Dev, Aherwar, and Patnaik (2019) used concept of Entropy weights to select automotive piston component. Singh, Sharma, and Srivastava (2019) proposed an integrated framework for aviation fuel consumption reduction based on entropy. Mohammed (2019) and Govindan, Agarwal, Darbari, and Jha (2019) used TOPSIS to select logistic providers on their supply chain projects. In view of these successful examples, this study builds the decision-making model with entropy and TOPSIS. Construction of the decisionmaking model in this study is consisted of three steps. First, expert forecasting was conducted to compile expert opinions on the appropriate criteria for the optimization plan for excess plant warehouse storage. Second, objective weights of different criteria for the optimization plan were calculated using entropy. Finally, the final results of the optimization plan were calculated using TOPSIS.

\subsubsection{Entropy}

Entropy can be used to estimate the amount of information contained in each piece of data and calculate its relative weight (Xu, Ma, Lian, $\mathrm{Xu}, \&$ Chaima, 2018). Entropy is originally a measure of physical phenomena, specifically, the degree of disorder or randomness of molecules in a system in a certain state (Shannon, 1948). The lower the entropy is, the more neatly arranged the molecules are, and the closer the system is to a perfect crystal (Shannon, 1948). Conversely, the higher the entropy is, the less regularly arranged the molecules are, and the greater the randomness in the system becomes. Entropy weighting involves calculating relative weights among different properties. In this study, the weights of individual properties of different plan options were first calculated to determine the extent to which they could communicate information relevant to decision-making, thereby indicating the uncertainties in the communication of information pertaining to decision-making. The weights of the different criteria were then compared to determine their relative importance. The calculation of entropy weights proceeded as follows (Xu et al., 2018): 
Step 1. Establish the D decision-making matrix.

The $\mathrm{D}$ decision-making matrix can be shows as follows:

$$
D=\frac{A_{1}}{A_{2}} \begin{gathered}
C_{i 1} \\
A_{i} \\
\vdots \\
A_{m}
\end{gathered}\left[\begin{array}{cccccc}
C_{21} & C_{22} & \cdots & \cdots & C_{2 j} & C_{2 n} \\
\vdots & \vdots & \cdots & \vdots & \vdots & \vdots \\
C_{i 1} & C_{i 2} & \vdots & \vdots & C_{i j} & C_{i n} \\
\vdots & \vdots & \cdots & \vdots & \vdots & \vdots \\
C_{m 1} & C_{m 2} & \cdots & \cdots & C_{m j} & C_{m n}
\end{array}\right] .
$$

In Matrix $D, A_{1}, A_{2}, A_{3} \ldots, A_{m}$ indicates the number of plans, and $C_{1}, C_{2}, C_{3} \ldots, C_{n}$ refer to decision-making criteria.

Step 2. Determine the $r_{i j}$.

The equation for the target property $P_{i j}$ can be expressed as follows:

$$
r_{i j}=\frac{C_{i j}}{\sqrt{\sum_{j=1}^{n} C_{i j}^{2}}},
$$

where $j=1, \ldots, n, i=1, \ldots, m$.

Step 3. Determine the $E_{j}$.

The weight measurement result of the target property is defined. The weight range here should be $0 \leq E_{j} \leq 1$, where $k$ is a positive constant, and $k=\frac{1}{\ell n m}$ ( $m$ is the number of plans involved in decision-making).

$$
E_{j}=-K \sum_{i=1}^{m} P_{i j} \ell n P_{i j}, \quad \forall j
$$

Step 4. Determine the $d_{j}$.

The ranks of the target property's result are distributed.

$$
d_{j}=1-E_{j}, \quad \forall j
$$

Step 5: Determine the $W_{j}$.

The expected comparative equal weight is as follows:

$$
W_{j}=\frac{d_{j}}{\sum_{j=1}^{n} d_{j}}, \quad \forall j .
$$

\subsubsection{TOPSIS}

Multi-property decision-making primarily involves calculating an optimal plan through evaluating the relative importance of the properties (Ghorabaee, Amiri, Zavadskas, Hooshmand, \& Antucheviciene, 2017; Stanujkic, Zavadskas, Karabasevic, Turskis, \& Kersuliene, 2017). This method is appropriate for a limited number of plan options that are typically discrete and already known. According to the problem's properties, decision-making methods can be 
divided into subjective and objective ones. In TOPSIS, proposed by Hwang and Yoon (1981), the decision-maker determines a positive ideal solution (PIS) and a negative ideal solution (NIS). The distance between the evaluated plan and the PIS is then calculated. The advantage of this method is that it enables the priorities of the evaluated plans to be determined according to their relative distance from the ideal solution, thereby avoiding the problem of incomparability between plans that are either equally close to the PIS or distant from the NIS (Stankevičienè, Kraujalienè, \& Vaiciukevičiūtè, 2017; Gavurova, Belas, Kocisova, \& Kliestik, 2017). A solution can be obtained using the following steps (Lin \& Cho, 2018).

Step 1. Establish a normalized evaluation matrix.

Establish a normalized evaluation matrix using the following equation:

$$
r_{i j}=\frac{C_{i j}}{\sqrt{\sum_{i=1}^{m} X^{2}{ }_{i j}}},
$$

where $i$ is a plan option, $j$ is an evaluation criterion, and $X_{i j}$ indicates the value of $i$ evaluated using $j$.

Step 2. Establish a normalized weighting matrix. $\left(w=\left(w_{1}, w_{2}, \ldots, w_{j} \ldots, w_{n}\right)\right)$ by the normalized evaluation matrix, as follows: ${ }_{j=1}^{m} W_{j}$

$$
V=\left[\begin{array}{cccc}
V_{11} & V_{12} & \cdots & V_{1 n} \\
V_{21} & V_{22} & \cdots & V_{2 n} \\
\vdots & \vdots & \cdots & \vdots \\
V_{m 1} & V_{m 2} & \cdots & V_{m n}
\end{array}\right]=\left[\begin{array}{cccc}
w_{1} r_{11} & w_{2} r_{12} & \cdots & w_{n} r_{1 n} \\
w_{1} r_{21} & w_{2} r_{22} & \cdots & w_{n} r_{2 n} \\
\vdots & \vdots & \cdots & \vdots \\
w_{1} r_{m 1} & w_{2} r_{m 2} & \cdots & w_{n} r_{m n}
\end{array}\right]
$$

Step 3. Determine the PIS and NIS.

The PIS and NIS is derived by the performances in the normalized weighting matrix. This procedure is to determine the PIS and NIS calculated from equation (12) and (13), respectively:

$$
\begin{aligned}
& A^{*}=\left\{\left(\max V_{i j} \mid j \in J\right),\left(\min V_{i j} \mid j \in J^{\prime}\right), i=1,2, \ldots, m\right\}, \\
& A^{-}=\left\{\left(\min V_{i j} \mid j \in J\right),\left(\max V_{i j} \mid j \in J^{\prime}\right), i=1,2, \ldots, m\right\},
\end{aligned}
$$

where $J$ is associated with the criteria that indicate profits or benefits and $J^{\prime}$ is associated with the criteria that indicate costs or losses.

Step 4. Determine the distance between the ideal and negative ideal solutions for each alternative.

$n$-dimensional Euclidean distance is used to calculate the separation measures. The separation of each alternative from the PIS is given as:

$$
S_{i}^{*}=\sqrt{\sum_{j=1}^{n}\left(V_{i j}-V_{j}^{*}\right)^{2}}, i=1,2, \ldots, m .
$$


Similarly, the distances from the NIS are calculated as

$$
S_{i}^{-}=\sqrt{\sum_{j=1}^{n}\left(V_{i j}-V_{j}^{-}\right)^{2}}, i=1,2, \ldots, m .
$$

Step 5. Determine the relative closeness of each alternative to the ideal solution.

Calculate the relative closeness of the plan options to the ideal solution, as indicated by a $C_{i}^{*}$ value close to 1 .

$$
C_{i}^{*}=\frac{S_{\mathrm{i}}^{-}}{S_{\mathrm{i}}^{*}+S_{\mathrm{i}}^{-}} .
$$

Step 6. Prioritize the calculated $C_{i}^{*}$ values to determine the optimal plan.

This method is consistent with intuitive decision-making and can be easily understood and accepted by decision-makers. However, because this method cannot process qualitative problems, it must be used in combination with other methods. Nonetheless, one study showed that the TOPSIS was able to determine the priorities of objects of comparison most clearly. Because the TOPSIS involves evaluation of both the PIS and NIS, it can prevent decision-makers from neglecting needs different stakeholders when making critical decisions and help them achieve the optimal solution. This study adopted weighting to obtain consistent and objective advices from experts regarding the priorities of plans, after which the optimal plan was designed using a TOPSIS-based calculation process for decision-making. By integrating weighting with the TOPSIS, this study was able to quantify decision-making at objective and consistent weights, thus lending greater persuasiveness to the plans calculated with higher priorities. The use of the designed method to obtain an optimization plan for resolving excess warehouse storage in Enterprise A was thus determined to be feasible.

\section{Case implementation and analysis}

Case implementation and analysis can be divided into three parts: 3.1 briefly introduces Enterprise A; 3.2 analyzes the problem existing in Enterprise A's current logistics and operational model; 3.3 gives research analysis of Enterprise A after implementing the method and model prosed in the second part above. Finally, raise the suggestions on optimization proposal in Section 4.

\subsection{Introduction of Enterprise A}

Focusing on the Internet and e-commerce, Enterprise A is an outstanding enterprise engaged in e-commerce talent cultivation, online marketing and planning, online brand-building, and other services for businesses selling products online. The original Enterprise A team has 14 years of experience in e-commerce services and 9 years of successful experience in handling retail businesses. Its scope of business includes various types of e-commerce, including business-to-business, business-to-consumer, consumer-to-consumer, and online-to-offline operations, thus giving it sufficient knowledge of e-commerce brand operations. Because of its long-term experience and background in e-commerce, Enterprise A has also been engaged 
in e-commerce-related training at the invitation or commission of local government, industry associations, and universities. Its main business is handling e-commerce operations as a third partner (TP), and it also provides tailored training courses for various organizations to cultivate talent in online business and e-commerce.

\subsection{Analysis of Enterprise A’s current logistics and operational model}

Enterprise A is a TP management service provider (MSP) in Shuyang County that trains plant and flower farmers to become skilled e-commerce vendors. It has accumulated relevant experience in cooperating with numerous brick-and-mortar plant shops. In addition to selfowned online plant shops, Enterprise A cooperated with numerous brick-and-mortar plant growers to help them launch online selling platforms. According to onsite investigations and survey analysis, this study determined the following main problems in Enterprise A's business operations: (a) slow information communication, (b) mixture of high-quality and low-cost products in logistics services, and (c) decline of overall online operations quality due to mutual interactions of different types of problems. The major problems are detailed in the following subsections.

(1) Slow information communication.

Enterprise A helps providers manage their online shops by receiving, compiling, and printing orders for them. After compiling the orders, it delivers them to the providers in person. The providers then prepare and pack the goods and dispatch them to logistics service providers for delivery to the end users. This can lead to untimely order updates among providers, and order backlogs and errors due to manual processing are likely to occur. During peak seasons and large sales campaigns, a surge in orders within a short time can result in preparation and delivery delays, which in turn cause increased customer complaints and decreased service quality.

(2) Mixture of high-quality and low-cost products in logistics services

Because of the unique nature of plant products (i.e., high death and damage rates), such products require a higher-quality logistics service than that used for ordinary products. Therefore, logistics costs for plant products have remained high. Many shops would prefer to choose a cheaper logistics service providers to save costs, but when delivery fails their packages would be suspended, which would certainly lower the product survival rate.

(3) Decline of overall online operations quality due to mutual interaction of different problem types

When handling a large quantity of orders, providers are pressed by time, leading them to resort to simple packaging and delivery without proper care, thus resulting in damaged goods. The customer complaints that ensue increase the workload of the enterprise's customer service department and lower its overall service quality, diminish customers' shopping experience, and, in the most extreme scenario, may even lead to revocation of online shop operation rights by the platform provider.

The main cause of the excess warehouse storage in the e-commerce industry is an inability to timely identify and share market demand and update information between upstream and downstream companies in the supply chain, which affects all logistics procedures. As 
an e-commerce-based plant shop, Enterprise A also experienced this common problem. The plant industry represents a particular case among industries using e-commerce sales models because of the peculiar nature of its products (e.g., product appearance and shape). To solve the excess warehouse storage problem in this industry, sales quantity must be accurately estimated. Only by identifying the most up-to-date market sales conditions can the appropriate warehouse stock, type, and size be determined. In this study, a two-part model for solving the problem of excess warehouse storage was constructed and analyzed. An optimization plan was also provided to serve as a reference for decision-makers or managers in solving this problem.

\subsection{Research analysis for the case study}

This study proposed an optimization plan to solve the problem of excess warehouse storage encountered by e-commerce-based plant shops. First, a sales volume analysis was conducted for Enterprise A to understand past and forecast future sales, whereby the warehousing area could then be estimated on a reasonable basis. Subsequently, entropy and the TOPSIS were employed to construct a decision-making model for assessing the proposed plan. Finally, on the basis of this decision-making model, the idea of a cloud warehouse was proposed and incorporated into the optimization plans.

\subsubsection{Analysis of prediction model}

To build a warehouse that can satisfy the future growth requirements of Enterprise A, this enterprise's 2016-2017 sales statistics were analyzed. By observing statistical patterns and designing a suitable experiment, an optimal prediction model was built to estimate the 20182019 sales volume. These steps are elaborated as follows.

Step 1: Data collection.

The raw sales volume data for 2016-2017 were compiled and processed to produce a broken-line graph illustrating the relationship between sales volume and time. Under the limitation of the data's cardinal number, the time-series data were grouped into 48 sets each containing data for 15 days to amplify statistical patterns for trend analysis.

Step 2: The relationship between sales volume and time.

The 2016-2017 sales volume suggested a relatively strong relationship between sales volume and time, for which periodic patterns were found. The sales volume data for 2016 and 2017 individually were also compared, and the results showed that their trends overlapped considerably, thus verifying the existence of annual sales volume patterns and the possibility of constructing prediction models based on these patterns (Figure 2). Further observation of sales volume trends revealed two off-value and two peak-value periods in the annual data. Given that plants typically exhibit seasonal sales patterns, peak-season and off-season sales data were considered separately in times-series data analysis for establishing the prediction model.

Step 3: Determine the prediction model's goodness of fit.

The exponential smoothing model was used in the experiment to determine the prediction model's goodness of fit. For the parameter $\alpha$, future environmental conditions were 


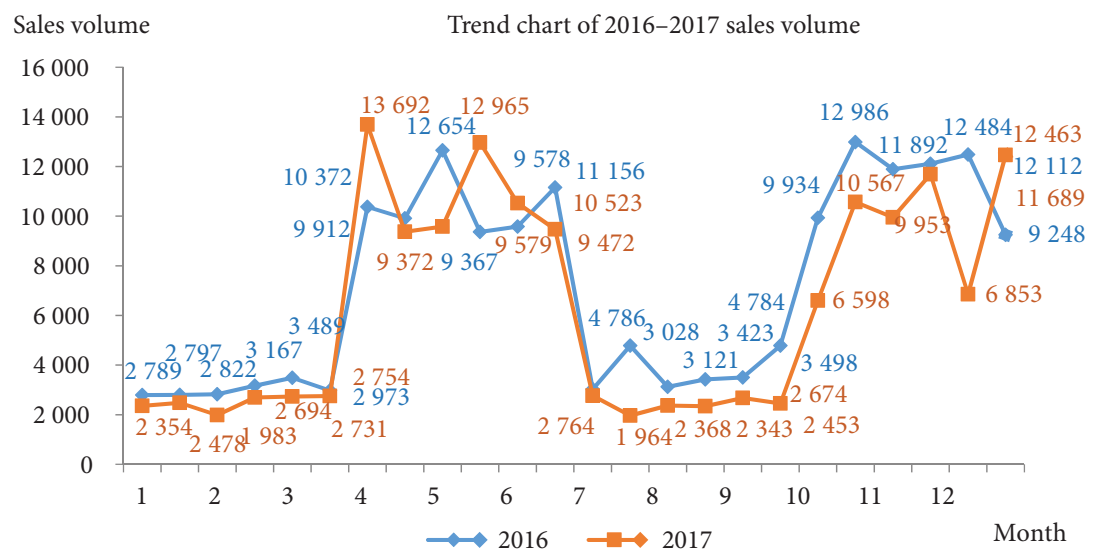

Figure 2. Comparison of 2016 and 2017 sales volume

assumed to be stable, and thus $\alpha=0.5$. Equation (1) was used to calculate the predicted single exponential smoothing value, with the result indicating relatively large fluctuations in terms of the prediction model's goodness of fit. The double exponential smoothing values (double values) were used to correct errors in the single exponential smoothing values (single values). According to the single values, the prediction values of the double exponential smoothing model could be obtained using Equations (2)-(4). Comparing the calculation results and actual sales volumes demonstrated that the model contained regular trends and had a mean error of 0.18 in the off-season and 0.19 in the peak season. Moreover, the mean errors were lower than those obtained using single exponential smoothing, namely 0.23 in the off-season and 0.25 in the peak season.

Step 4: Determine the time series model for sales volume.

The exponential smoothing model was adopted for making predictions, with its results adopted for predicting off-season and peak-season sales volumes.

Step 5: Determine the sales volume of predict.

The predicted 2018-2019 off-season and peak-season sales volumes were consolidated and averaged to produce a key reference value for the capacity of warehouses to be constructed (Figure 3). The average sales volume determined thereof was 6,843 .

\subsubsection{Analysis of decision-making model}

The proposed decision-making model was built in two stages. Stage 1 comprised five steps. First, appropriate decision-making criteria were identified using expert prediction, after which entropy was used to obtain the comprehensive objective weights of all expert predictions. The second stage had six steps, and the TOPSIS was applied to calculate the final results of the model. The stages and steps are detailed as follows.

Stage 1: Using expert predictions to identify appropriate decision-making criteria and plans.

The decision-making model comprised five steps. The various steps are detailed in the following subsections. 


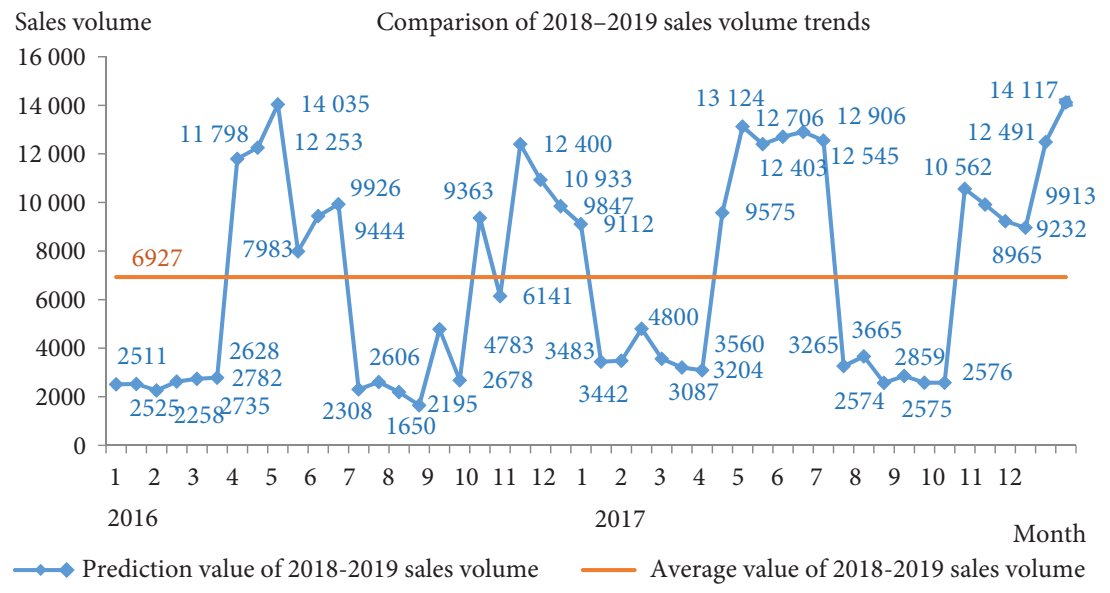

Figure 3. Comparison of 2018-2019 sales volume trend and mean

Step 1: Selecting members of the expert panel.

Ten members of the management were selected as experts in this study. The recruiting criteria for experts were(1) at least 3 years of practical experience in web-based marketing, (2) Level 3 certificates for data analyst and at least 5 years of experience in operating ecommerce companies, (3) at least 5 years of experience in e-commerce operation, and (4) at least 5 years of experience in the customer service and reception work. Two operating executives, two general directors for data analysis, two customer service executives, two marketing executives, and two leading online shop managers were selected for a total of ten experts.

Step 2: Decision-making model for model evaluation.

Experts were invited to discuss the model for building warehouses to resolve excess storage. The decision-making criteria were determined through brainstorming. The criteria were elaborated as follows.

1) Geographical location and conditions $\left(C_{1}\right)$ : Upon completion of the warehouse facilities, the favorable geographical location and conditions of said facilities can increase the efficiency and reduce the costs of logistics transportation.

2) Infrastructure conditions $\left(C_{2}\right)$ : Upon completion of the warehouse facilities, highquality infrastructure can enhance operating efficiency, thus facilitating the growth of development capacity.

3) Water and power supply conditions $\left(C_{3}\right)$ : Upon completion of the warehouse facilities, favorable water and power supply conditions assist management of these facilities. In particular, plant products must be stored in a place with adequate water and power supply to avoid losses due to plant death or damage during storage.

4) Logistics delivery and transportation conditions $\left(C_{4}\right)$ : Upon completion of the warehouse facilities, satisfactory conditions of logistics delivery and transportation can increase the efficiency of plant product delivery, enhance customer satisfaction, lower transportation costs, and increase revenue. 
5) Material loading, unloading, and stacking $\left(C_{5}\right)$ : Upon completion of the warehouse facilities, material loading and unloading efficiency can be enhanced, material stacking can be performed more properly, and operating efficiency can be substantially increased. The time required for loading and unloading operations can be substantially reduced to lower costs.

6) Labor costs $\left(C_{6}\right)$ : Different types of warehousing facilities entail different labor costs, which often account for $30 \%$ or more of total costs and represent one of the main costs of logistics operations. Therefore, labor costs must be considered under the principle of economy in different warehouse facility conditions.

7) Warehouse fees $\left(C_{7}\right)$ : Different types of warehouse facilities entail different warehouse fees, which often account for $30 \%$ or more of total costs and represent one of the main costs of logistics operations. Therefore, warehouse fees must be considered under the principle of economy in different warehouse facility conditions.

8) Technical level of warehouse functions $\left(C_{8}\right)$ : Upon completion of the warehouse facilities, their technical level plays a key role in the logistics system. By effectively and rationally utilizing warehousing technologies, resource flows can be accelerated to lower costs while ensuring successful production, thereby achieving effective resource control and management.

9) Service level $\left(C_{9}\right)$ : Upon completion of the warehouse facilities, a satisfactory service level can increase the operating efficiency of overall product logistics tasks, including loading, moving, storage, circulating, processing, and delivery, thereby meeting customer needs and improving customer satisfaction.

10) Three options were proposed in this study: (a) cloud warehouses, that is, temporary goods collection hubs established in each village to serve as virtual warehouses; (b) physical warehouses built according to company characteristics to store goods; (c) onsite warehouses, that is, greenhouses built on existing plant farms and utilizing farming land as storage space.

Step 3. Assigning weights to decision-making criteria.

Through the use of entropy, the criteria provided by the ten experts were substituted into Equation (5) to obtain the decision-making matrix $D$. The result of the target property was then substituted into Equation (6) to obtain $P_{i j}$. Entropy measurements, degrees, and weights were obtained using Equations (7)-(9), respectively (Table 1). The resulting criterion weights are presented in Tables 1 and 2.

Table 1. Entropy measurements, degrees, and weights

\begin{tabular}{|c|c|c|c|c|c|c|c|c|c|}
\hline & $C_{1}$ & $C_{2}$ & $C_{3}$ & $C_{4}$ & $C_{5}$ & $C_{6}$ & $C_{7}$ & $C_{8}$ & $C_{9}$ \\
\hline$E_{j}$ & 20.910 & 17.464 & 19.949 & 20.730 & 19.219 & 15.962 & 18.339 & 11.487 & 18.959 \\
\hline$d_{j}$ & 18.587 & 17.703 & 20.474 & 19.231 & 22.642 & 18.864 & 20.851 & 17.359 & 21.629 \\
\hline$W_{j}$ & 16.005 & 18.182 & 19.424 & 19.481 & 21.589 & 17.896 & 21.102 & 22.209 & 22.697 \\
\hline
\end{tabular}


Table 2. Weights of assessment criteria for Enterprise A's warehouse construction

\begin{tabular}{|l|l|}
\hline \multicolumn{1}{|c|}{ Criterion } & Weights \\
\hline Technical level of warehouse functions & 0.112 \\
\hline Service level & 0.107 \\
\hline Logistics delivery and transportation conditions & 0.113 \\
\hline Infrastructure conditions & 0.110 \\
\hline Water and power supply conditions & 0.114 \\
\hline Labor costs & 0.108 \\
\hline Material loading, unloading, and stacking & 0.110 \\
\hline Geographical location and conditions & 0.111 \\
\hline Warehouse fees & 0.115 \\
\hline
\end{tabular}

Stage 2: Using the TOPSIS to calculate assessment results of warehouse construction options.

For decision-making on warehouse construction for Enterprise A, the warehouse fee served as the primary assessment condition. Other conditions considered were water and power supply, logistics delivery and transportation, technical level of warehouse functions, geographical location and conditions, material loading, unloading, and stacking, infrastructure, labor costs, and service level. These conditions could be employed as criteria for preliminary assessment. A preliminary plan list, namely, the several possible plans to be decided on, was produced. Considering Enterprise A's actual circumstances, cloud warehouse, physical warehouse and on-site warehouse plans were selected for the decision-makers to evaluate according to the corresponding assessment criteria using the TOPSIS.

Step 1: Establishing a standardized assessment matrix and weighted matrix.

First, the experts scored each plan option according to the criteria and used Equation (10) to create a standardized matrix. Equation (11) was then used to multiply the objective weights of all criteria obtained through entropy by this standardized matrix. The results are presented in Table 3.

Table 3. Standardized matrix results

\begin{tabular}{|l|c|c|c|c|c|c|c|c|c|}
\hline & $C_{1}$ & $C_{2}$ & $C_{3}$ & $C_{4}$ & $C_{5}$ & $C_{6}$ & $C_{7}$ & $C_{8}$ & $C_{9}$ \\
\hline $\begin{array}{l}\text { Cloud } \\
\text { warehouse }\end{array}$ & 20.910 & 17.464 & 19.949 & 20.730 & 19.219 & 15.962 & 18.339 & 11.487 & 18.959 \\
\hline $\begin{array}{l}\text { Physical } \\
\text { warehouse }\end{array}$ & 18.587 & 17.703 & 20.474 & 19.231 & 22.642 & 18.864 & 20.851 & 17.359 & 21.629 \\
\hline $\begin{array}{l}\text { Onsite } \\
\text { warehouse }\end{array}$ & 16.005 & 18.182 & 19.424 & 19.481 & 21.589 & 17.896 & 21.102 & 22.209 & 22.697 \\
\hline
\end{tabular}


Step 2: Determining PIS, NIS, and separation measure.

Substituting the adjusted values of the assessment matrix into Equations 12 and 13, the PIS and NIS were obtained, whereas Equations 14 and 15 were used to obtain the separation measure.

Step 3: Determining the relative closeness $C_{i}^{*}$ and prioritizing the plan options.

The relative closeness $C_{i}^{*}$ was obtained using Equation 16. The plan options were then prioritized to determine the optimum one. Table 4 shows the results.

Table 4. Prioritizing TOPSIS results

\begin{tabular}{|l|c|c|c|c|}
\hline & PIS & NIS & Relative closeness & Optimization plan \\
\hline Cloud warehouse & 0.601 & 1.352 & 0.692 & 1 \\
\hline Physical warehouse & 0.637 & 0.973 & 0.604 & 2 \\
\hline Onsite warehouse & 1.401 & 0.578 & 0.292 & 3 \\
\hline
\end{tabular}

Step 4: Proposal for decision-making.

The optimization plan options were analyzed and prioritized according to the decisionmaking model, with the following result: cloud warehouse $(0.692)>$ physical warehouse $(0.604)>$ onsite warehouse $(0.292)$. Therefore, this study proposed that Enterprise A build a cloud warehouse, as the most favorable optimization plan option.

\section{Results and suggestions}

This study provided a reference for solving the excess warehouse storage encountered by e-commerce-based plant shops through developing optimization plans. According to the results, a cloud warehouse was adopted as the most satisfactory solution for Enterprise A. Cloud warehouse is a type of logistics warehousing that differs from conventional warehouses because it relies on a novel concept that integrates cloud computation, modern information management, and warehousing facilities to perform goods circulation. Therefore, compared to conventional warehouses, a cloud warehouse features highly efficient and precise management as well as automated equipment and digitalized systems. Based on a cloud warehouse, this study offered concrete suggestions for resolving excess warehouse storage in e-commerce-based plant shops. Based on the analysis results, the concrete suggestions for building a cloud warehouse are as follows: (1) establish temporary goods collection hubs at village entrances, (2) develop electronic information systems, and (3) devise a cloud warehouse configuration and define its functions.

\subsection{Establish temporary goods collection hubs at village entrances}

The enterprise in this case study is located in a national e-commerce demonstration site. All 10 administrative villages in this town were selected as China's Taobao Villages, thus making it the only town in China with such a high density of administrative villages (Li, 2017). These villages offer all e-commerce-related services, including facilities for temporary goods storage. By using this service, Enterprise A can collect goods from various plant providers 


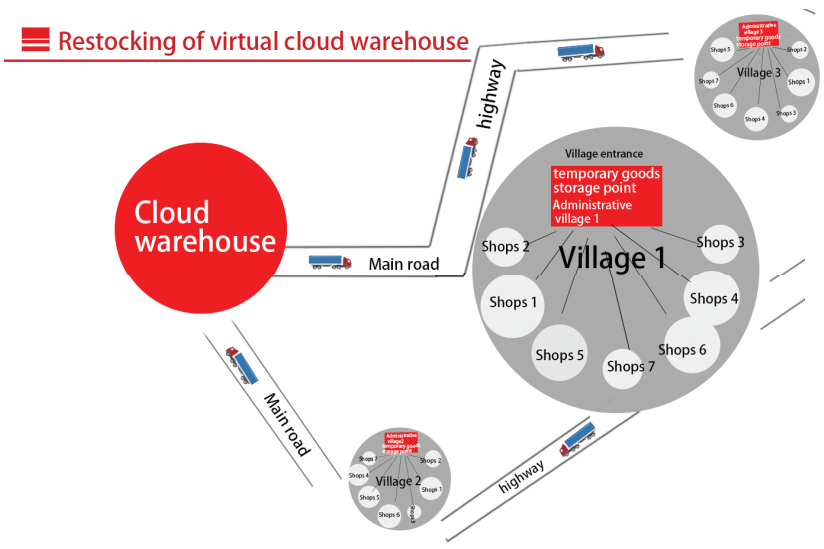

Figure 4. Restocking of virtual cloud warehouse

in different villages in a single location. Through calculation of the optimal route, transport vehicles only need to come once to transport goods stored at village entrances to the cloud warehouse for restocking. The basic idea is to regard the provider's location as a virtual warehouse. When an order from the information system is received by the provider, real-time supply and delivery can be achieved, thereby shortening delivery times and transportation costs (Figure 4).

\subsection{Develop electronic information systems}

Enterprise A should develop an information system for its cloud warehouse encompassing all the basic functions of a modern information system. This system should employ networkcontrolling systems and distributed real-time databases to integrate the real-time data (CLPS) from enterprise resource planning (ERP), the WMS, and the original equipment manufacturer. The integrated data are then transferred to the TP MSP for centralized management and deployment, whereby information transfer speed, work efficiency, and logistics delivery and speed are all enhanced and the client complaint rate lowered. Finally, the order processing efficiency of Enterprise A should be increased and its total costs decreased.

\subsection{Devise a cloud warehouse configuration and define its functions}

Because of the characteristics of plant products, suitable storage, processing, and packaging functions should be considered when designing the cloud warehouse. This should also serve as the basis for planning warehouse operational procedures. Moreover, building a barcodescanning area for incoming plants, an automated allocation system, an onsite freshnesskeeping warehouse, packaging and sorting areas, and a barcode-scanning area for outgoing plants can enhance the efficiency of product delivery from the warehouse and improve the packaging quality and plant survival rate. In addition, goods can be sent from warehouses and delivered to end customers in batches to lower transportation frequency. Figure 5 illustrates the configuration and functional planning of the cloud warehouse. 


\section{Master plan of the information system of the cloud warehouse}

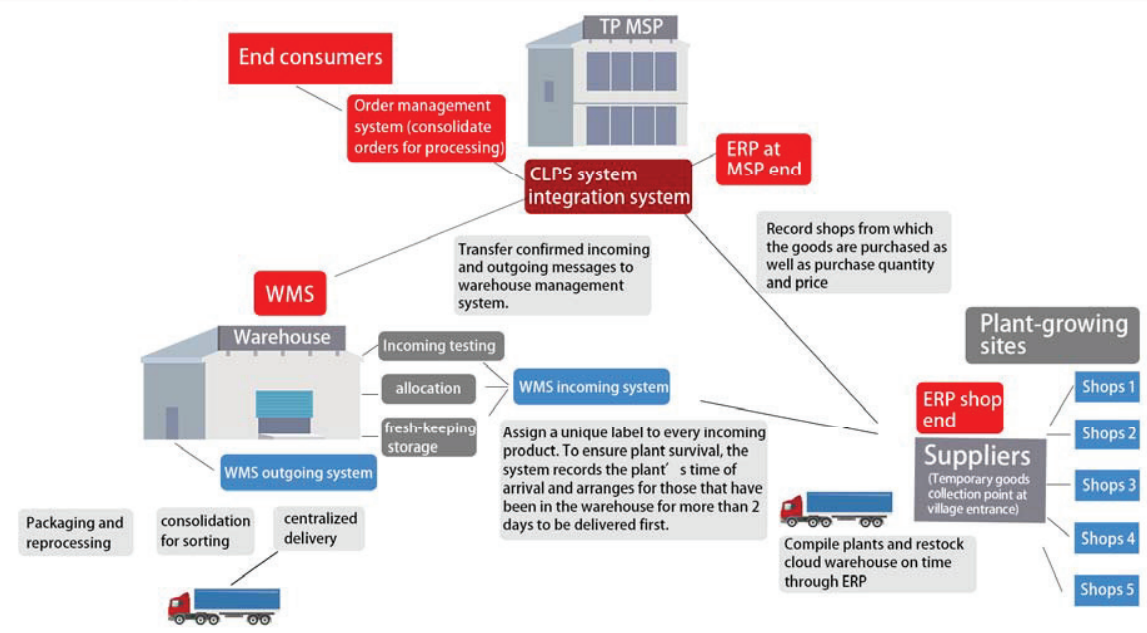

Figure 5. Information system master plan

\section{Discussion}

This study adopted qualitative and quantitative scientific methods to solve the problem of excess warehouse storage for Enterprise A, further optimizing this solution with the idea of a cloud warehouse. Enterprise A built their warehouse according to the suggestions given in the study, and has reported a gradual reduction in excess warehouse storage in the peak season. These conclusions and suggestions can serve as a reference for decision-makers or executives in e-commerce-based plant shops and other e-commerce-related industries for solving the problem of excess warehouse storage.

Enterprise A has gradually completed the construction according to the specific suggestions, and the excess warehouse storage situation has been constantly improved. As shown in table 5, the pre-optimization and the process of optimization was analyzed. By observing various indexes of storage quality and storage efficiency before optimization in June 2017, gradual improvement in optimization could be discovered. Several indicators have shown concrete improvement, especially in the rate of dead or damage good dropped from the original $26.8 \%$ to $8.2 \%$, inventory accuracy rate increased from $81.5 \%$ to 92.6 , and back order rate has been lowered from $25.5 \%$ to $5.6 \%$. From the observation of storage cost in financial aspect, after the implement of the project, the cost raised slightly from 240,315 RMB (201701 06) to 2,630,030 RMB (201801 06). Although the cost is higher than the situation before the implement of the project, it was greatly reduced in the year after the introduction. The increased cost was derived from the process of system introduction during the connection of old and new projects. In addition, the same result can be observed in the financial profit indicator due to the negative correlation between cost and profit. It can be seen from the benefit analysis of Enterprise A that the construction of cloud warehouse decreased the storage cost and increased the profit, so enterprise can reap profit from the effective control. 
On the whole, even the Enterprise A has not yet completed the construction of all the suggestions and plans, still it is believed that the entire organization's logistics operation will be well under way and obtain higher profits, also will operate sustainably in the competitive environment after the completion of optimization in the near future.

Table 5. The results for benefit analyses

\begin{tabular}{|c|c|c|c|c|c|}
\hline \multirow{3}{*}{ Criteria } & \multirow{3}{*}{ Quantitative indicators } & \multicolumn{2}{|c|}{ Before optimization } & \multicolumn{2}{|c|}{ After optimization } \\
\hline & & \multicolumn{4}{|c|}{$\longrightarrow$} \\
\hline & & $201701 \sim 06$ & $201707 \sim 12$ & 201801 06 & $201807 \sim 11$ \\
\hline \multirow{5}{*}{$\begin{array}{l}\text { Storage } \\
\text { quality }\end{array}$} & Order Picking Accuracy (\%) & 94.5 & 95.1 & 96.3 & 97.4 \\
\hline & $\begin{array}{l}\text { Stock Losses or Damages } \\
\text { (RMB) }\end{array}$ & 26.8 & 22.5 & 10.3 & 8.2 \\
\hline & Inventory Accuracy (\%) & 81.5 & 85.3 & 91.5 & 92.6 \\
\hline & Back Order Rate (\%) & 45.5 & 18.5 & 8.4 & 5.6 \\
\hline & Perfect Order Rate (\%) & 64.3 & 76.2 & 87.8 & 89.3 \\
\hline \multirow{3}{*}{$\begin{array}{l}\text { Storage } \\
\text { efficiency }\end{array}$} & Inventory Turnover Rate (\%) & 1.4 & 2.3 & 2.4 & 2.8 \\
\hline & $\begin{array}{l}\text { Warehouse Ground Area } \\
\text { Utilization Rate (\%) }\end{array}$ & 68.3 & 73.2 & 84.8 & 87.5 \\
\hline & $\begin{array}{l}\text { Logistics Installation and Equip- } \\
\text { ment Utilization Rate (\%) }\end{array}$ & 78.3 & 81.4 & 88.2 & 90.3 \\
\hline \multirow{2}{*}{ Finance } & Storage Cost (RMB) & 240315 & 280140 & 2630030 & 2455000 \\
\hline & Profit (RMB) & 2013060 & 1848654 & 2250600 & 23207400 \\
\hline
\end{tabular}

\section{Conclusions}

This study provided a reference for solving the excess warehouse storage encountered by e-commerce-based plant shops through developing optimization plans. According to the results, a cloud warehouse was adopted as the most satisfactory solution for Enterprise A. A cloud warehouse is a type of logistics warehousing that differs from conventional warehouses because it relies on a novel concept that integrates cloud computation, modern information management, and warehousing facilities to perform goods circulation. Importantly, the proposed models, methods and suggestions provided to decision-makers or executives can not only solve the problem of excess warehouse storage, but set a reference in how academic theory in the e-commerce plant industry or other related e-commerce industries, making it highly applicable for academic and commercial purposes.

This study applies the theoretical basis put forward by the past studies to practical cases along with the concept, method and model of help the Enterprise A solve the problems in actual situation. However, there are still some research limitations in the study which will be specified as follow, and specific suggestions will be made for the future studies. 


\section{(1) Research Limitations.}

This study adopted a case to investigate and discuss the problems e-commerce-based plant shops through developing optimization plans to solve the problem of excess warehouse storage. Limitations to this study are described as follows.

(a) Sampling and model selection: The data in this study was sampled in 2016 and 2017, and the data was still insufficient. Although it is the big data era, the more data collected, the better result can be obtained. However, the plant industry is an emerging industry and Enterprise A has only been established for three years, the problem of excess warehouse storage does exist in some ways. According to Lewis (1982), the research can produce reasonable prediction as the amount of data is more than 20 records. Therefore, at present, it can only solve the problems that lies in reality for Enterprise A with scientific and systematic methods. The simple exponential smoothing model is mainly used as a prediction model in this study. The prime reason why other models were not taken into account is that the extensiveness and simplicity of exponential smoothing model in data analysis; moreover, this model has been widely applied to solve practical problems in business successfully. (b) Research area and participants: The case study method is adopted to present the optimization suggestions of cloud warehouse concept for Enterprise A and to extrapolate the entire plant industry. However, due to the difference of environment and other conditions, it is impossible to overgeneralize in other cases.

(2) Research suggestion

In view of the above research limitations, the suggestions for the future research are as follows. (a) Sampling and model selection: If future studies are not limited by the data volume, the data volume can be divided into different stages for trend analysis, such as short-term (1-3 years), medium-term (3-5 years) and long-term (5 years or more). Different models are applied to simulate the results of different stages, and more accurate models are selected for analysis. Finally, the corresponding specific suggestions are proposed. (b) Research area and participants: although this study can solve the problems faced by Enterprise A at present, it is suggested that the area and object of future research can be more widely selected to verify the proposal of cloud warehouse concept in this study.

\section{References}

Bao, L. W., Huang, Y. C., Ma, Z. J., Zhang, J., \& Lv, Q. C. (2012). On the supply chain management supported by e-commerce service platform for agreement based circulation of fruits and vegetables. Physics Procedia, 33, 1957-1963. https://doi.org/10.1016/j.phpro.2012.05.308

China's e-Commerce Research Center. (2017). China's e-Commerce of plant market statistic report.

Dev, S., Aherwar, A., \& Patnaik, A. (2019). Material selection for automotive piston component using entropy-VIKOR method. Silicon. https://doi.org/10.1007/s12633-019-00110-y

Dianawati, F., Surjandari, I., \& Nafitri, R. (2012). Forecasting methods for determining the level of safety stock in electronic industry. In S. Sethi, M. Bogatai, L. Ros-McDonnell (Eds.), Industrial engineering: Innovative networks (pp. 359-366). Springer. https://doi.org/10.1007/978-1-4471-2321-7_40

Gavurova, B., Belas, J., Kocisova, K., \& Kliestik, T. (2017). Comparison of selected methods for performance evaluation of Czech and Slovak commercial banks. Journal of Business Economics and Management, 18(5), 852-876. https://doi.org/10.3846/16111699.2017.1371637 
Ghorabaee, M. K., Amiri, M., Zavadskas, E. K., Hooshmand, R., \& Antucheviciene, J. (2017). Fuzzy extension of the CODAS method for multi-criteria market segment evaluation. Journal of Business Economics and Management, 18(1), 1-19. https://doi.org/10.3846/16111699.2016.1278559

Govindan, K., Agarwal, V., Darbari, J. D., \& Jha, P. C. (2019). An integrated decision making model for the selection of sustainable forward and reverse logistic providers. Annals of Operations Research, 273(1-2), 607-650. https://doi.org/10.1007/s10479-017-2654-5

Hoseinpour, M., Sadrnia, H., Ghobadian, B., \& Tabasizadeh, M. (2019). Exhaust emission characteristics of a diesel engine on gasoline fumigation: an experimental investigation and evaluation using the MCDM method. International Journal of Environmental Science and Technology, 16(2), 9951004. https://doi.org/10.1007/s13762-018-1667-1

$\mathrm{Hu}$, J. (2018). E-commerce big data computing platform system based on distributed computing logistics information. Cluster Computing. https://doi.org/10.1007/s10586-018-2074-6

Hu, K. Y., \& Chang, T. S. (2010). An innovative automated storage and retrieval system for B2C ecommerce logistics. International Journal of Advanced Manufacturing Technology, 48(1-4), 297-305. https://doi.org/10.1007/s00170-009-2292-4

Hwang, C., \& Yoon, K. (1981). Multiple attribute decision making: Methods and application. New York: Springer Publications. https://doi.org/10.1007/978-3-642-48318-9

Hyndman, R. J., Akram, M., \& Archibald, B. C. (2008). The admissible parameter space for exponential smoothing models. Annals of the Institute of Statistical Mathematics, 60(2), 407-426. https://doi.org/10.1007/s10463-006-0109-x

Jiao, Z. (2016). Service mode and development trend of the "last-mile delivery" of e-commerce logistics. Contemporary Logistics in China, 239-261. https://doi.org/10.1007/978-981-10-1052-1_11

Koster, R. B. M. D., Johnson, A. L., \& Roy, D. (2017). Warehouse design and management. International Journal of Production Research, 55(21), 6327-6330. https://doi.org/10.1080/00207543.2017.1371856

Lewis, C. D. (1982). Industrial and business forecasting model. London: Butterworths.

Li, A. H. F. (2017). E-commerce and taobao villages: A promise for China's rural development? China Perspectives, 3, 57-62.

Lin, H. L., \& Cho, C. C. (2018). An ideal model for a merger and acquisition strategy in the information technology industry a case study for investment in the Taiwanese industrial personal computer sector. Journal of Testing and Evaluation. https://doi.org/10.1520/JTE20170106

Liu, S. (2018). E-shop transshipment selection evaluation based on cloud model. Journal of Shanghai Jiaotong University (Science), 23(5), 643-649. https://doi.org/10.1007/s12204-018-1978-X

Liu, J., Liu, C., Zhang, L., \& Xu, Y. (2019). Research on sales information prediction system of e-commerce enterprises based on time series model. Information Systems and e-Business Management. https://doi.org/10.1007/s10257-019-00399-7

Mohammed, A. (2019). Towards a sustainable assessment of suppliers: an integrated fuzzy TOPSISpossibilistic multi-objective approach. Annals of Operations Research. https://doi.org/10.1007/s10479-019-03167-5

Ramanathan, R. (2010). E-commerce success criteria: determining which criteria count most. Electronic Commerce Research, 10(2), 191-208. https://doi.org/10.1007/s10660-010-9051-3

Shannon, C. E. (1948). A mathematical theory of communication. The Bell System Technical Journal, 27(3), 379-423. https://doi.org/10.1002/j.1538-7305.1948.tb01338.x

Singh, J., Sharma, S. K., \& Srivastava, R. (2019). AHP-Entropy based priority assessment of factors to reduce aviation fuel consumption. International Journal of System Assurance Engineering and Management. https://doi.org/10.1007/s13198-019-00758-0

Stankevičienè, J., Kraujalienė, L., \& Vaiciukevičiūtė, A. (2017). Assessment of technology transfer office performance for value creation in higher education institutions. Journal of Business Economics and Management, 18(6), 1063-1081. https://doi.org/10.3846/16111699.2017.1405841 
Stanujkic, D., Zavadskas, E. K., Karabasevic, D., Turskis, Z., \& Kersuliene, V. (2017). New group decision-making ARCAS approach based on the integration of the SWARA and the ARAS methods adapted for negotiations. Journal of Business Economics and Management, 18(4), 599-618. https://doi.org/10.3846/16111699.2017.1327455

Vercher, E., Corberan-Vallet, A., Segura, J. V., \& Bermudez, J. D. (2012). Initial conditions estimation for improving forecast accuracy in exponential smoothing. TOP, 20(2), 517-533. https://doi.org/10.1007/s11750-011-0221-9

Wakabayashi, K., Suzuki, K., Watanabe, A., \& Karasawa, Y. (2014). Analysis and suggestion of an ecommerce logistics solution: effects of introduction of cloud computing based warehouse management System in Japan. In P. Golinska (Ed.), Logistics operations, supply chain management and sustainability (pp. 567-573). Springer. https://doi.org/10.1007/978-3-319-07287-6_40

Xu, H. S., Ma, C., Lian, J. J., Xu, K., \& Chaima, E. (2018). Urban flooding risk assessment based on an integrated k-means cluster algorithm and improved entropy weight method in the region of Haikou. China, Journal of Hydrology, 563, 975-986. https://doi.org/10.1016/j.jhydrol.2018.06.060

Yang, C., Lan, S., \& Huang, G. Q. (2019). Revenue sharing model in New Hong Kong's warehousing business paradigm. Journal of Ambient Intelligence and Humanized Computing, 10(3), 883-892. https://doi.org/10.1007/s12652-018-0822-3

Zhang, M., Huang, G. Q., Xu, S. X., \& Zhao, Z. (2016). Optimization based transportation service trading in B2B e-commerce logistics. Journal of Intelligent Manufacturing. https://doi.org/10.1007/s10845-016-1287-x 